\title{
The use of Scanning Vibrating Electrode Technique to Evaluate the Effect of Hot Stamping on the Corrosion Resistance of 22MnB5 press-hardened Steel Electroplated with Zn-Ni
}

\author{
Camila Pucci Couto $^{a, b *}{ }^{\infty}$, Isolda Costa ${ }^{a}$, Barbara Victoria Gonçalves de Viveiross ${ }^{a}$, Maicon Cavalieri \\ de Alencar ${ }^{a}$, Marco Antonio Colosio ${ }^{c}, Z_{\text {Zehbour Panossian }}^{b}$, Jesualdo Luiz Rossi ${ }^{a}{ }^{\circledR}$ \\ ${ }^{a}$ Instituto de Pesquisas Energéticas e Nucleares, Centro de Ciência e Tecnologia de Materiais, Av. Prof. \\ Lineu Prestes 2242, CEP 05508-000, São Paulo, SP, Brasil \\ ${ }^{b}$ Instituto de Pesquisas Tecnológicas, Laboratório de Corrosão e Proteção, Av. Prof. Almeida Prado \\ 532, CEP 05508-901, São Paulo, SP, Brasil \\ ${ }^{c}$ General Motors Mercosul, Av. do Estado 2880, CEP 09550-900, São Caetano do Sul, SP, Brasil
}

Received: February 22, 2019; Revised: November 12, 2019; Accepted: November 28, 2019

\begin{abstract}
Carmakers must achieve the worldwide targets for lightweight materials, safety and reducing the fuel consumption. The use of press-hardened steel (PHS), in vehicle structures has been contributing with these requirements. This type of steel is widely used for the hot-stamping which consists in heating the steel blank to total austenitization temperature and then transferring it from the furnace into the die tool where the steel is formed and quenched at the same time. PHS is usually protect with metallic coatings in order to avoid both steel oxidation and decarburization. Hot-dip Al-Si coating is currently the main used in this application. However, alternative coatings, like zinc-based, are under investigation. This work aims at evaluating the corrosion resistance of the 22MnB5 grade PHS, electroplated with $\mathrm{Zn}-\mathrm{Ni}$, before and after hot stamping, using the scanning vibrating electrode technique (SVET). Results from SVET showed that samples prior to hot stamping, the corrosion mechanism was uniform over the exposed surface, and was mainly related to selective dissolution of zinc from the coating. On the other hand, hot stamped samples showed localized corrosion mechanism with decrease in current with time of immersion due to the formation of corrosion products on the exposed surface.
\end{abstract}

Keywords: PHS, metallic coatings, electroplated $\mathrm{Zn}-\mathrm{Ni}$, SVET.

\section{Introduction}

The application of hot stamped components in the automotive industry is steadily increasing. It is a strategic product that helps the automakers satisfies the safety needs and fuel reduction requirements by means of the lightweight design concept, a current trend for new vehicles ${ }^{1-4}$.

Press-hardened steels (PHS) are boron-manganese steels classified as ultra-high strength steel (UHSS). They are usually used for the hot stamping, achieving at the end of the process a tensile strength up to 1,500 MPa. Moreover, the spring back effect is not seen, as a consequence of the steel chemical composition combined with high temperatures during the hot stamping process ${ }^{3,56-8}$. The steel grade of PHS widely applied in the automotive industry is known as $22 \mathrm{MnB} 5$ which comprises of $0.23 \% \mathrm{C}, 1.50 \% \mathrm{Mn}$ and $0.003 \% \mathrm{~B}$ in mass ${ }^{4,9}$.

The hot-stamping process consists of the following steps: heating a steel blank at total austenitization temperatures, around $900{ }^{\circ} \mathrm{C}$ for $10 \mathrm{~min}$ and then transferring the steel blank into the press tooling for forming and fast cooling to provide the fully martensitic transformation. At the beginning of the process, the steel exhibits around $600 \mathrm{MPa}$ of tensile strength due to its ferrite-perlite microstructure; at the end, the tensile strength increases up to $1,500 \mathrm{MPa}$ as a consequence of the martensitic transformation ${ }^{4,9-12}$.

*e-mail: camila.puccicouto@usp.br
Due to the high hot stamping temperatures, it is unavoidable to have steel decarburization and oxidation by means of the contact with the atmospheric air during the transferring step of the blank from the furnace into to the press tooling $4,7,9$, $10,13,14$. Moreover, the iron oxide layer shows high hardness which results in a premature wear of the die tooling $3,4,9$. In order to avoid the steel decarburization, oxidation and to ensure good corrosion resistance, metallic coatings are applied on the steel substrate $4,7,9,10,15$.

For hot-stamping applications the hot-dip metallic coating Al-Si is the most commonly used on 22MnB5 steel substrate. Besides the phase formation which occurs during hot-dipping, there is an influence of the hot stamping on the phases transformation, due to the diffusion process which takes place ${ }^{13,16}$.

Alternative coatings, such as electroplated $\mathrm{Zn}-\mathrm{Ni}$, have been under investigation to evaluate their potential for replacement of Al-Si coatings, in order to keep up with the high projected world demand for this type of steel ${ }^{7}$. Zincbased coatings are advantageous comparatively to the Al-Si because they provide cathodic protection to the steel substrate whereas the mechanism of protection of Al-Si coatings against corrosion is by barrier $7,9,13,17-19$.

The more commercially attractive composition of $\mathrm{Zn}-\mathrm{Ni}$ alloys comprise from $10 \%$ to $15 \% \mathrm{Ni}$ (in mass). These alloys show high corrosion resistance, formability and weldability ${ }^{20-22}$. 
The coating is characterized by micro roughness, refined microstructure and good thermal stability ${ }^{7}$. An oxide layer is formed after the hot stamping which is beneficial since it prevents the reduction of the $\mathrm{Zn}$ by evaporation. In addition, the presence of $\gamma-\mathrm{Ni}_{5} \mathrm{Zn}_{21}$ intermetallic, uniformly distributed prevents liquid metal embrittlement of the steel, during the hot forming process which is very common in the Fe- $\mathrm{Zn}$ system at high temperatures ${ }^{7,20,22}$.

In the present work the corrosion behavior of $22 \mathrm{MnB} 5$ steel coated with electroplated $\mathrm{Zn}-\mathrm{Ni}$ was evaluated by means of scanning vibrating electrode technique (SVET) before and after the hot stamping process. Furthermore, the surface morphologies were characterized by means of field emission gun - scanning electron microscopy (FEG-SEM).

\section{Materials and Methods}

The surface of 22MnB5 steel electroplated with $\mathrm{Zn}-\mathrm{Ni}$ samples were investigated by means of scanning vibration electrode technique (SVET) and field emission gun - scanning electron microscopy (FEG-SEM), before and after hot stamping.

FEG-SEM analyses were carried out in backscattering electron mode (EBS); the semi-quantitative composition of the different phases was given by energy dispersive spectroscopy (EDS) detector. For surface characterization, the samples were only cold cut using a guillotine and the surface was cleaned with isopropyl alcohol.

Scanning vibrating electrode technique (SVET) tests were carried out using equipment controlled by an automated scanning electrode. Insulated Pt-Ir probes with platinum black deposited were used as vibrating electrode for the SVET system. The probe was placed $(100 \pm 9) \mu \mathrm{m}$ above the surface, vibrating in the planes perpendicular $(\mathrm{Z})$ and parallel $(\mathrm{X})$ to the sample's surface. The amplitude of vibration was $19 \mu \mathrm{m}$, vibration frequencies of the probe were $174 \mathrm{~Hz}(\mathrm{X})$ and 73 $\mathrm{Hz}(\mathrm{Z})$. The scanning was carried out over the exposed area obtaining maps of $30 \times 24$ points, with distance in points of $100 \mu \mathrm{m}$. A time lag between acquiring each current density data-point was $0.5 \mathrm{~s}$. All experiments were performed in a Faraday cage at $(20 \pm 1){ }^{\circ} \mathrm{C}$. The $22 \mathrm{MnB} 5$ steel sample used as working electrode was fixed in an epoxy sample holder with beeswax and the area to be analyzed was also circumscribed with beeswax. The surface was not polished, due to the surface characteristics; the polish would remove this layer. An adhesive tape and the epoxy resin were used as a reservoir for the electrolyte. The experiments were performed during continuous immersion in $0.001 \mathrm{~mol} \cdot \mathrm{L}^{-1} \mathrm{NaCl}$ for 24 $\mathrm{h}$; mappings were obtained every $2 \mathrm{~h}$. An external reservoir was used with $60 \mathrm{~mL}$ of electrolyte to maintain constant the level inside the test reservoir; a peristaltic pump maintained the low flux of the solution with flow rate of approximately 3 $\mathrm{mL} \cdot \mathrm{min}^{-1}$, in order to avoid the corrosion products dispersion.

\section{Results and Discussion}

The surface morphology of the 22MnB5 steel electroplated with $\mathrm{Zn}-\mathrm{Ni}$ and its respective EDS is shown in Figure 1. This figure shows that the coating is scratched and some parts of the surface was removed leading to irregular finishing, likely due to processes, such as coiling or packaging. The EDS semi-quantitative analysis showed that the coating consists mainly of zinc $(\approx 80 \%)$, nickel $(\approx 15 \%)$ and low oxygen content, indicating that a slight oxidising process occurred at the surface.
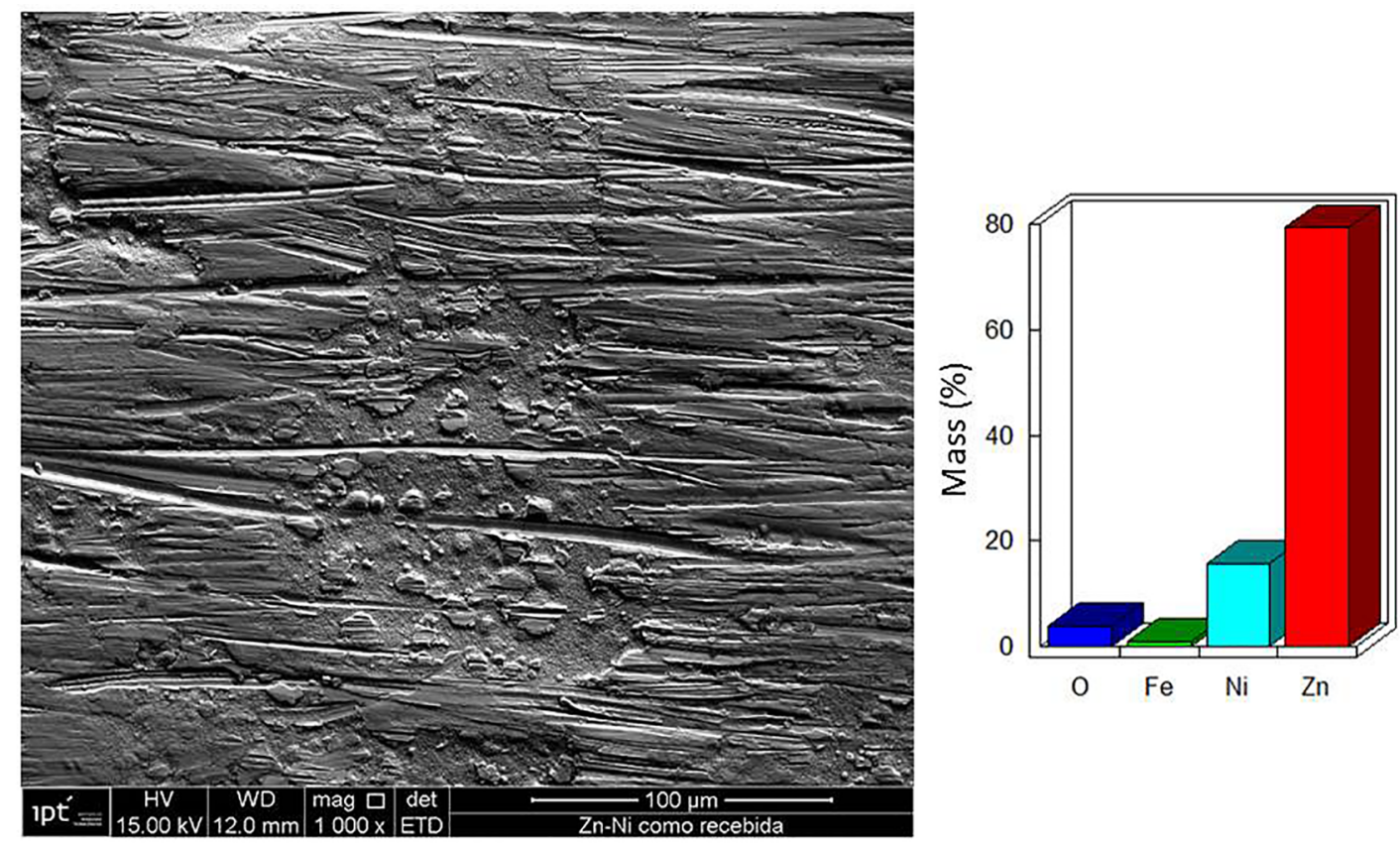

Figure 1. Surface morphology of 22MnB5 steel electroplated with $\mathrm{Zn}-\mathrm{Ni}$ and its respective composition 
The corrosion behaviour of $22 \mathrm{MnB} 5$ steel protected with electroplated $\mathrm{Zn}-\mathrm{Ni}$ coating was evaluated by means of a SVET test. The results are shown in Figure 2 which revealed the corrosion process of $22 \mathrm{MnB} 5$ steel protected with electroplated $\mathrm{Zn}-\mathrm{Ni}$ in the span of $24 \mathrm{~h}$. The green areas indicate non-electrochemistry activity, in other words, net current near to zero; on the other hand, the red and blue areas correspond to positive (anodic) and negative (cathodic) currents, respectively ${ }^{23}$.

As seen in Figure 1, a corrosion process began to develop on the exposed surface since the first hours of test but the attack occurred in a uniform and generalized way. However, from $16 \mathrm{~h}$ of test, there was an indication of anodic currents at the left side of the sample (red colour) with corresponding cathodic currents (blue colour) in the vicinities of the anodic areas. A selective dissolution of zinc (reaction 1 - red areas) at the weakest areas of the $\mathrm{Zn}-\mathrm{Ni}$ coating and the oxygen reduction reaction (reaction 2 - blue areas) must be the reason for this behaviour, as indicated in reactions 1 and 2 .

$$
\begin{gathered}
Z n \rightarrow Z^{2+}+2 e^{-} \\
\mathrm{O}_{2}+2 \mathrm{H}_{2} \mathrm{O}+4 e^{-} \rightarrow 4 \mathrm{OH}^{-}
\end{gathered}
$$

The corrosion resistance of $\mathrm{Zn}-\mathrm{Ni}$ electroplated coatings on metallic substrates depends on the coating composition and structure. Increasing its nickel content leads to more noble open circuit potentials, i.e., the corrosion resistance of the coating is enhanced if barrier properties are concerned ${ }^{20}$, ${ }^{24}$. However, depending on the coating nobility, it might not provide cathodic protection to the steel substrate and the mechanism of the protection against corrosion would be by barrier ${ }^{22,25}$.

Figures 3 and 4 show the surface morphology of 22MnB5 steel electroplated with $\mathrm{Zn}-\mathrm{Ni}$ after hot stamping and the chemical composition of the coating obtained by EDS. Figure 3 , shows that the surface morphology is heterogeneous and cracks resulted from the stamping process. Figure 4 shows details of the defects in the coating shown in Figure 3. Different regions in the coating were identified and characterized by means of EDS. Region 1 is an iron rich one; region 2 is zinc enriched, while region 3 is similar to the coating prior to hot stamping. The enrichment in iron is due to the diffusion

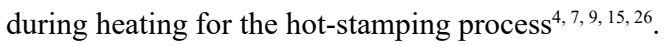

The nickel content in the electroplated coating changed during hot stamping. Before the thermo-mechanical process, the average nickel content was about $15 \%$ (mass) but it decreased to values lower than $5 \%$ (mass) with the original $\mathrm{Zn}-\mathrm{Ni}$ alloy observed preferably around the rich iron region.

Few studies investigated the corrosion resistance behaviour of the 22Mn5B steel electroplated with $\mathrm{Zn}-\mathrm{Ni}$ after hot stamping considering the increase of iron content in the coating layer but none of them used SVET in their investigation ${ }^{4}$.

SVET results for hot stamped samples are presented in Figure 5. A comparison of SVET results of the coated PHS, prior to (Fig. 2) and after hot stamping (Fig. 5), shows lower currents for the hot stamped samples. This might be explained by the exposure of the substrate, leading to galvanic coupling between coating and substrate and, consequently, lower net currents being detected by SVET maps. Also,

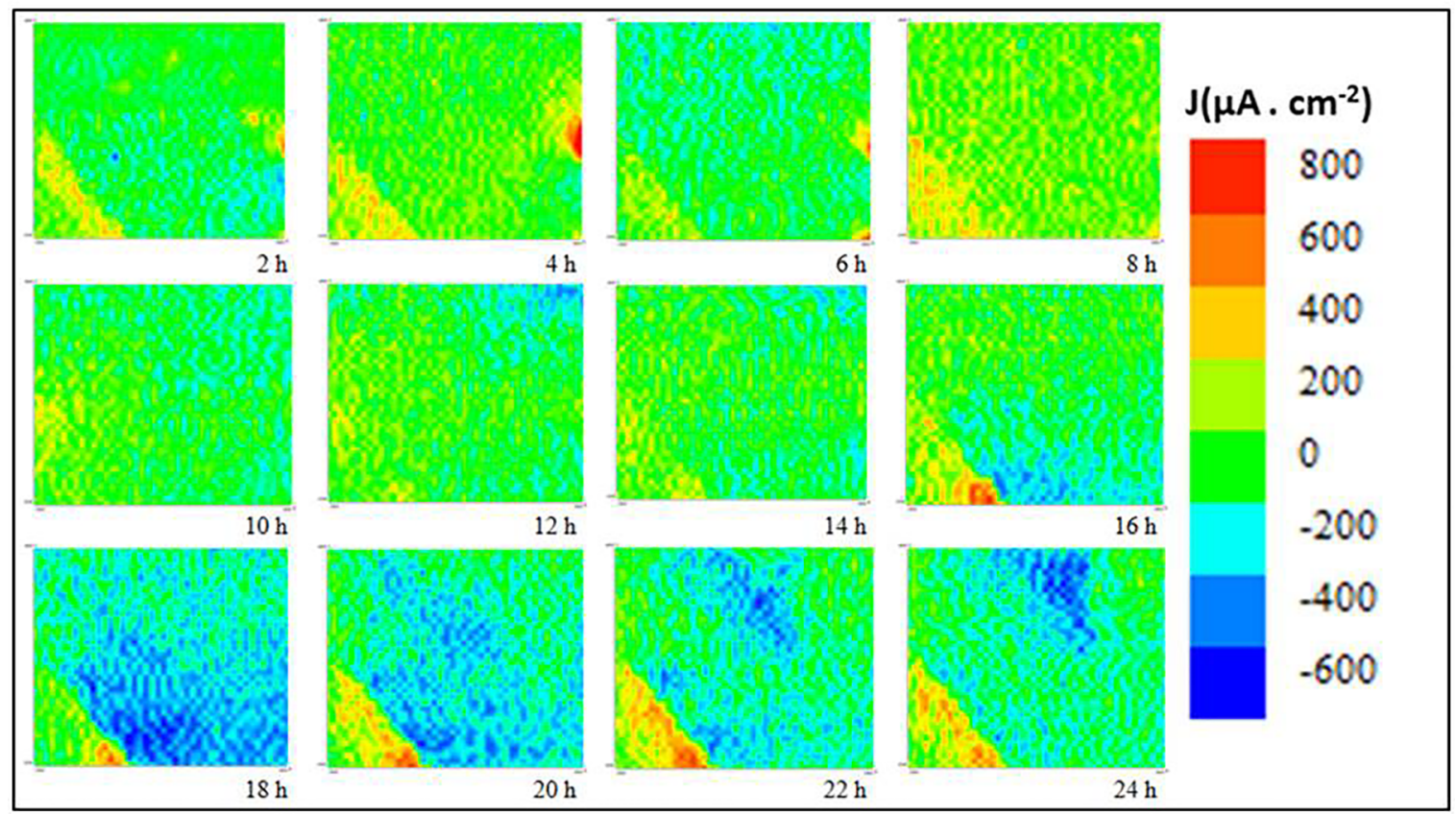

Figure 2. SVET maps showing the development of corrosion on the 22MnB5 steel electroplated with $\mathrm{Zn}-\mathrm{Ni}$ along $24 \mathrm{~h}$ of immersion in $0.001 \mathrm{~mol} \cdot \mathrm{L}^{-1} \mathrm{NaCl}$ solution 

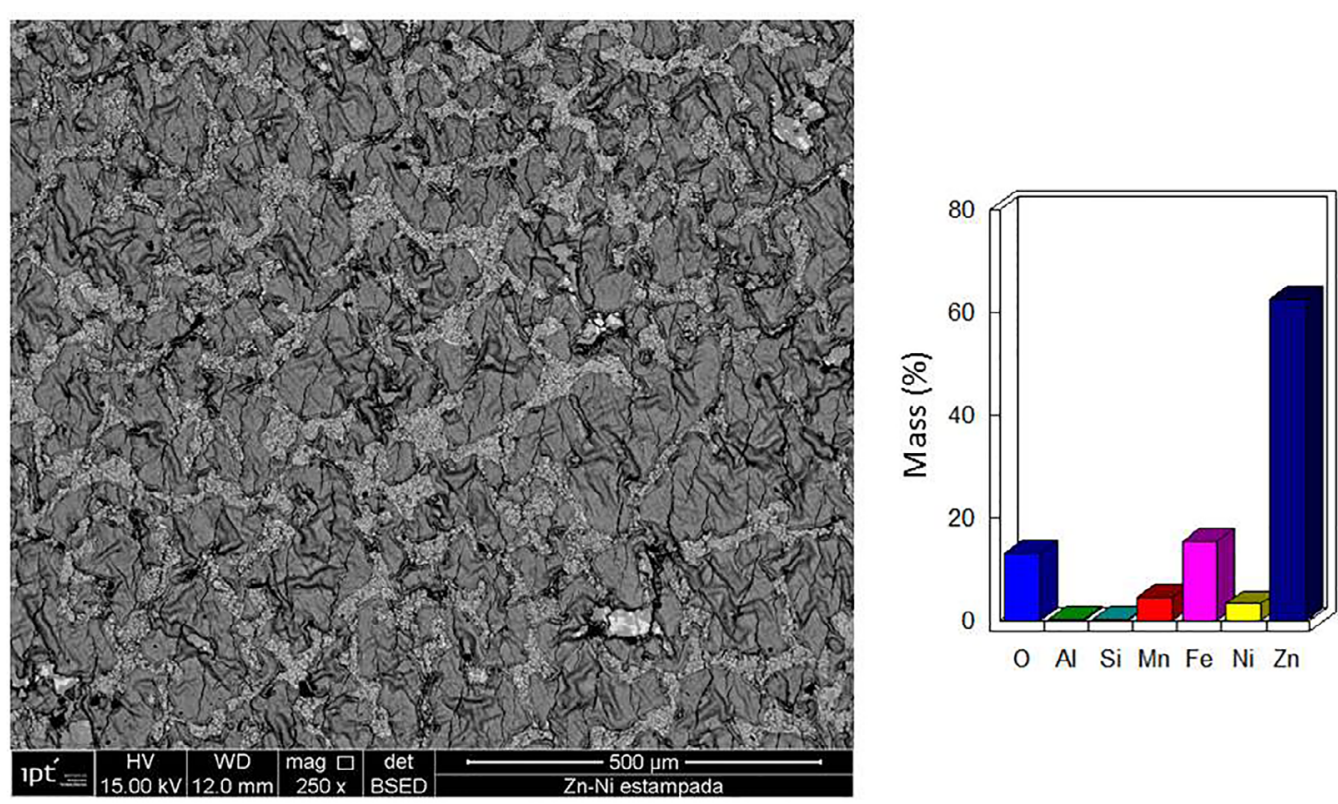

Figure 3. Surface morphology of 22MnB5 steel coated with electroplated with Zn-Ni coating after hot stamping.
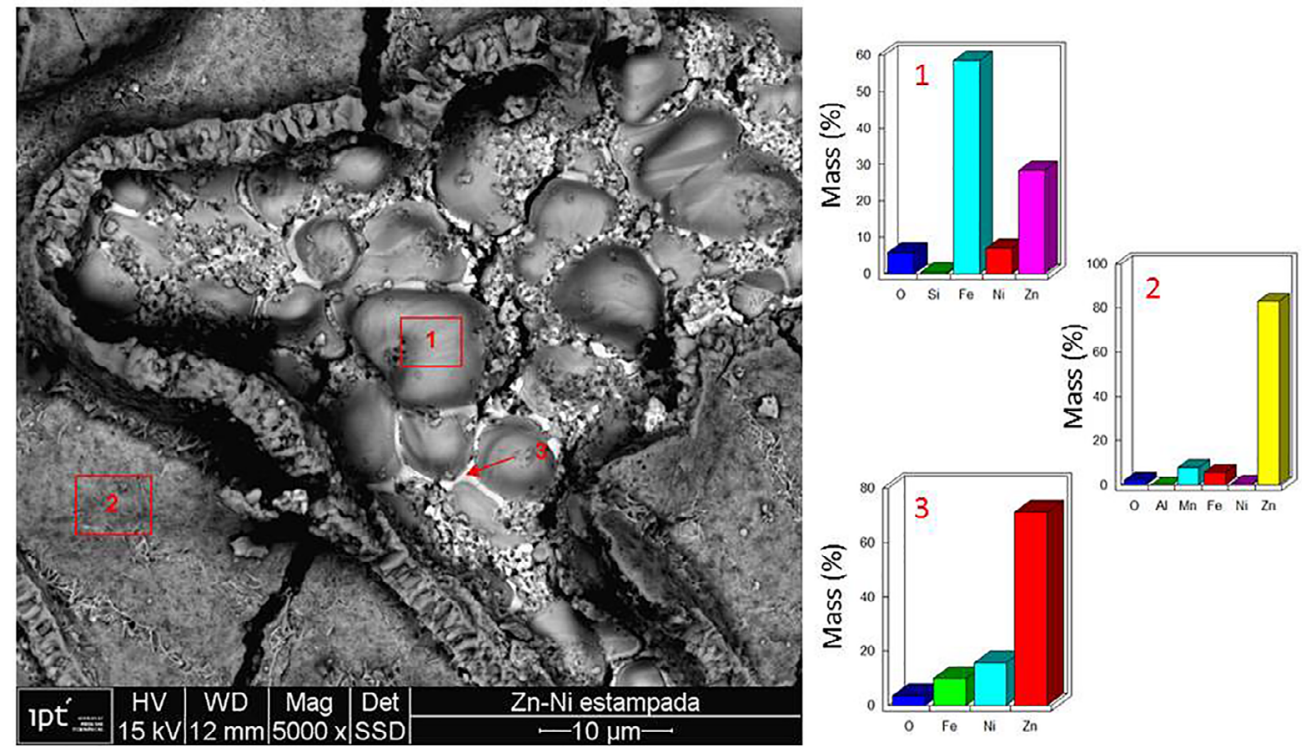

Figure 4. Details of the surface of the 22MnB5 steel electroplated with $\mathrm{Zn}$-Ni coating after hot stamping, showing different aspects of the coating.

the anodic and cathodic currents were homogenously distributed at the surface, although few spots indicative of electrochemical activity were seen after $8 \mathrm{~h}$ of test and these slowly increased with time of exposure to the corrosive environment $\left(0.001 \mathrm{~mol} \cdot \mathrm{L}^{-1} \mathrm{NaCl}\right)$. The differences in the mechanism of corrosion attack between the samples with the $\mathrm{Zn}$-Ni coating, before and after stamping, were related to the defects that exposed the substrate, to the changes of the coating composition and morphology and resulted in a homogeneous type of attack.

Based on the results that showed iron enrichment of the coating after hot stamping, it is likely that the dissolution of iron (reaction 3) contributes to the anodic reaction and the surrounding areas are cathodically protected by the anodic regions.

$$
F e \rightarrow F e^{2+}+2 e^{-}
$$

Despite the contribution of iron dissolution to the anodic currents measured in hot stamped samples, the galvanic coupling promoted by the defects that exposed the substrate, in this kind of samples, resulted in lower currents measured (Fig. 2) compared to the samples with a coating that protected the substrate by barrier effect (Fig. 5). 


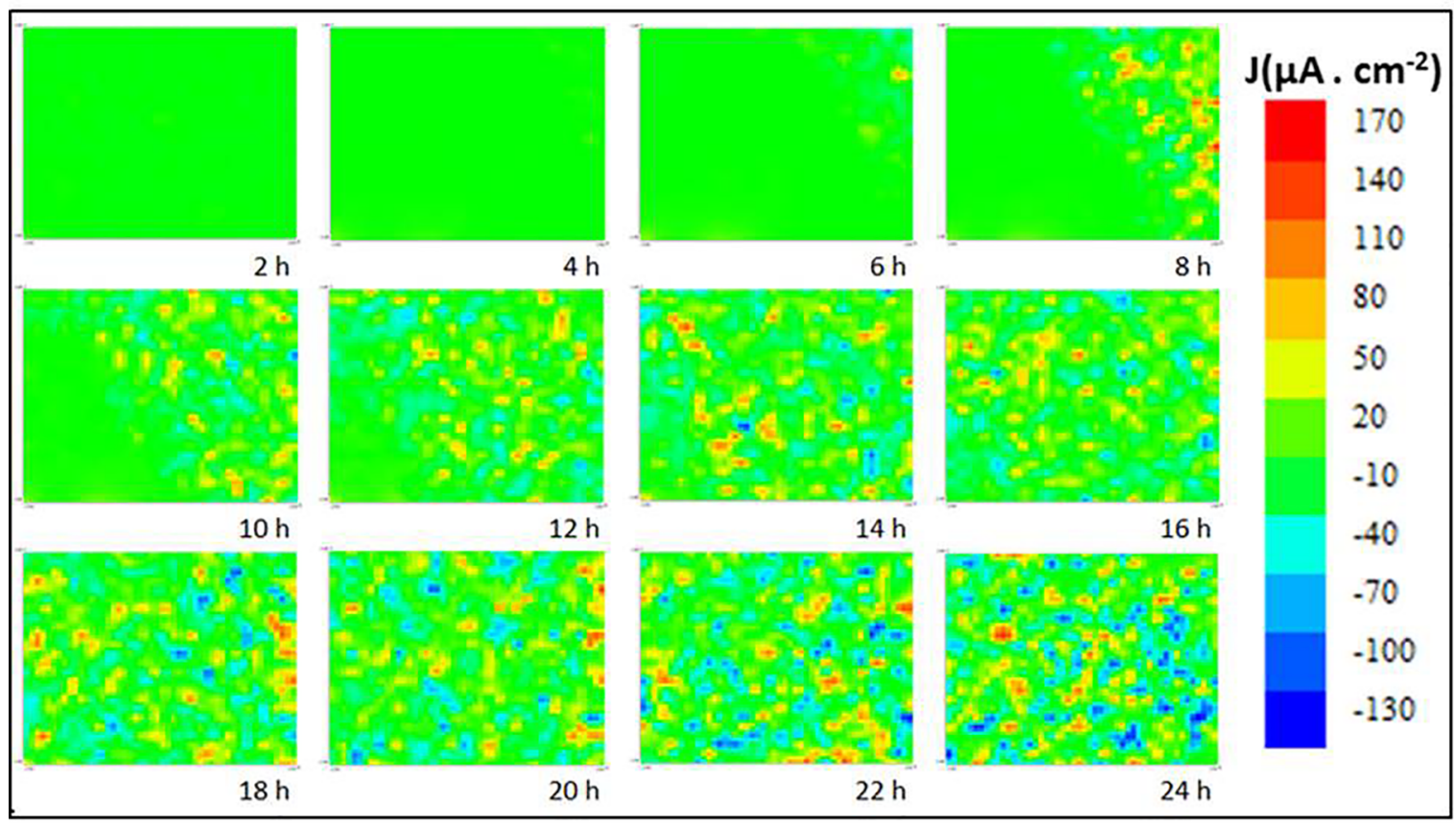

Figure 5. SVET maps showing the corrosion behaviour of hot stamped $22 \mathrm{MnB} 5$ steel coated with electroplated $\mathrm{Zn}-\mathrm{Ni}$ during $24 \mathrm{~h}$ of immersion on $0.001 \mathrm{~mol} \cdot \mathrm{L}^{-1} \mathrm{NaCl}$ solution

\section{Conclusion}

Hot stamping of 22Mn5B steel electroplated with $\mathrm{Zn}-\mathrm{Ni}$ resulted in a diffusion of elements from the steel substrate and led to an iron enrichment of the coating. Defects were also generated in the $\mathrm{Zn}-\mathrm{Ni}$ coating by hot stamping and, thus, the mechanism of corrosion protection changed. The lack of defects exposing the substrate in the samples before hot stamping and the significant amount of $\mathrm{Ni}$ in the coating (nearly $15 \%$ (mass)) resulted in a barrier type of protection. Hot stamping, however, led to iron diffusion into the surface reducing the $\mathrm{Ni}$ content in the coating to approximately $5 \%$ (mass), exposing the substrate and resulting in a cathodic protection of the exposed substrate by the $\mathrm{Ni}$-impoverished layer.

SVET was an effective method for evaluation of the corrosion mechanism of the PHS with $\mathrm{Zn}$-Ni coating.

\section{Acknowledgements}

This study was supported by the Coordenação de Aperfeiçoamento de Pessoal de Nivel Superior (CAPES) Finance Code 001 and by the Fundação de Apoio ao Instituto de Pesquisas Tecnológicas (FIPT).

\section{References}

1. Palm C, Vollmer R, Aspacher J, Gharbi M. Increasing performance of hot stamping systems. Procedia Engineering. 2017;207:765-70.

2. Lei C, Xing Z, Xu W, Hong Z, Shan D. Hot stamping of patchwork blanks: modelling and experimental investigation. International Journal of Advanced Manufacturing Technology. 2017;92(5-8):2609-17.
3. Mori K, Bariani PF, Behrens BA, Brosius A, Bruschi S, Maeno $\mathrm{T}$, et al. Hot stamping of ultra-high strength steel parts. CIRP Annals. 2017;66(2):755-77.

4. Karbasian H, Tekkaya AE. A review on hot stamping. Journal of Materials Processing Technology. 2010;210(15):2103-118.

5. Wagoner RH, Lim H, Lee MG. Advanced issues in springback. International Journal of Plasticity. 2013;45:3-20.

6. Bao J, Liu H, Xing Z, Song B, Yang Y. Springback of hot stamping and die quenching with ultra-high-strength boron steel. Engineering Review. 2013;33(3):151-156.

7. Kondratiuk J, Kuhn P, Labrenz E, Bischoff C. Zinc coatings for hot sheet metal forming: comparison of phase evolution and microstructure during heat treatment. Surface and Coatings Technology. 2011;205(17-18):4141-53.

8. Merklein M, Lechler J. Investigation of the thermo-mechanical properties of hot stamping steels. Journal of Materials Processing Technology. 2006;177(1):452-5.

9. Fan DW, Cooman BC. State-of-the-knowledge on coating systems for hot stamped parts. Steel Research International. 2012;83(5):412-33

10. Fan DW, Kim HS, Birosca S, Cooman BC. Critical review of hot stamping technology for automotive steels. Materials Science and Technology. 2007;99-110.

11. Wang B, Zhang JY, Fan JF, Zhao SL, Ren SB, Chou KC. Modelling of melt flow and solidification in the twin-roll strip casting process. Steel Research International. 2009;80(3):218-22.

12. Naganathan A, Penter L. Hot stamping. In: Altan T, Tkkaya $\mathrm{AE}$, editors. Sheet metal forming-processes and applications. Materials Park, OH: ASM International. 2012. p. 133-42.

13. Fan DW, Kim HS, Oh JK, Chin KG, Cooman BC. Coating degradation in hot press forming. ISIJ International. 2010;50(4):561-8. 
14. Gui ZX, Wang K, Zhang YS, Zhu B. Cracking and interfacial debonding of the Al-Si coating in hot stamping of pre-coated boron steel. Applied Surface Science. 2014;316(15):595-603.

15. Windmann M, Röttger A, Theisen W. Formation of intermetallic phases in Al-coated hot-stamped 22MnB5 sheets in terms of coating thickness and Si content. Surface and Coatings Technology. 2014;246:17-25.

16. Fan DW, Cooman BC. State-of-the-knowledge on coating systems for hot stamped parts. Steel Research International. 2012;83(5):412-33.

17. Cho L, Kang H, Lee C, Cooman BC. Microstructure of liquid metal embrittlement cracks on Zn-coated 22MnB5 presshardened steel. Scripta Materialia. 2014;90-91(1):25-8.

18. Panossian Z, Mariaca L, Morcillo M, Flores S, Rocha J, Peña $\mathrm{JJ}$, et al. Steel cathodic protection afforded by zinc, aluminium and zinc/aluminium alloy coatings in the atmosphere. Surface and Coatings Technology. 2005;190(2-3):244-8.

19. Allély C, Dosdat L, Clauzeau O, Ogle K, Volovitch P. Anticorrosion mechanisms of aluminized steel for hot stamping. Surface and Coatings Technology. 2014;238:188-96.

20. Byk TV, Gaevskaya TV, Tsybulskaya LS. Effect of electrodeposition conditions on the composition, microstructure, and corrosion resistance of $\mathrm{Zn}-\mathrm{Ni}$ alloy coatings. Surface and Coatings Technology. 2008;202(24):5817-23.

21. El Hajjami A, Gigandet MP, Petris-Wery M, Catonne JC, Duprat JJ, Thiery L, et al. Characterization of thin Zn-Ni alloy coatings electrodeposited on low carbon steel. Applied Surface Science. 2007;254(2):480-9.

22. Wilcox GD, Gabe DR. Physical properties of electrodeposits. Corrosion Science. 1993;35(5-8):1251-8.

23. Bastos AC, Quevedo MC, Karavai OV, Ferreira MGS. On the application of the scanning vibrating electrode technique (SVET) to corrosion research. Journal of the Electrochemical Society. 2017;164(14):973-990.

24. Tafreshi M, Allahkaram SR, Farhangi H. Comparative study on structure, corrosion properties and tribological behavior of pure $\mathrm{Zn}$ and different $\mathrm{Zn}-\mathrm{Ni}$ alloy coatings. Materials Chemistry and Physics. 2016;183:263-72.

25. Conde A, Arenas MA, Damborenea JJ. Electrodeposition of $\mathrm{Zn}-\mathrm{Ni}$ coatings as Cd replacement for corrosion protection of high strength steel. Corrosion Science. 2011;53(4):1489-97.

26. Windmann M, Röttger A, Theisen W. Phase formation at the interface between a boron alloyed steel substrate and an Al-rich coating. Surface and Coatings Technology. 2013;226:130-9. 